\title{
TRADE UNCERTAINTY AND SPECIALIZATION. SOCIAL VERSUS PRIVATE PLANNING ${ }^{* * *}$
}

\author{
BY
}

CHARLES VAN MARREWIJK* AND PETER A.G. VAN BERGEIJK**

\section{INTRODUCTION}

Foreign traders have to deal with uncertainty. Relative prices and exchange rates are characterized by high volatility. Government interventions in foreign trade are widespread. Clearly, this uncertainty concerning foreign trade conditions must influence the desired amount of trade and the extent of specialization.

Uncertainty can be introduced by assuming state dependence of endowments, preferences, technology and prices (Pomery 1984). Most theoretical papers dealing with uncertainty follow the seminal article by Ruffin (1974) and focus on (relative) prices as the source of uncertainty in trade. Uncertainty concerning the traded quantities appears, however, equally important. Tariffs, quotas, embargoes and boycotts may be imposed unexpectedly. Market shares can be lost in a short lapse of time. The literature on market disruption, however, does not seem to deal satisfactorily with this source of uncertainty in foreign trade. Bhagwati and Srinivasan (1976) examine the optimal policy intervention required in an exporting country when there is a possibility of a market-disruption-induced trade restriction being invoked by the importing country. Mayer (1977) deals with a country's optimal trade policy when embargoes and other trade interruptions are threatening. Optimal policy choices, however, depend on the behaviour of both individual consumers and individual producers. It seems reasonable to assume that the costs of trade disruptions will be internalized by economic units that trade with foreign economic units. Hence, as Tolley and Wilman (1977) show in a partial equilibrium framework, an embargo probability should lead to private adjustments to curtail consumption and expand production. Their analysis, however, is restricted to the consequences of decreasing possibilities to import and neglects the effects

* University of Groningen, Faculty of Economics, Groningen.

** Ministry of Economic Affairs, DG-BEB, The Hague. This article communicates the opinion of the author. The views expressed herein are not necessarily shared by his employer.

*** Comments by Willem Buiter, Casper de Vries and participants at the Buiter Workshop Series at the University of Groningen (May 1989) were very useful. 
in the exporting sector of the economy. Moreover, they do not make clear whether or not private decision making is superior to collective action.

In this paper we seek to formalize the case of trade disruption in a traditional neoclassical model of international trade. In the Appendix we generalize our results for an arbitrary, but finite, number of goods. A small trading economy will be studied that faces given terms of trade in combination with an uncertain volume of trade. The model is essentially a two-period model, since the country decides on the optimal pattern of domestic production before the possible volume of trade is known. It cannot change the allocation of production factors once this decision has been taken. For simplicity we assume two extreme possible states of the world: one in which any quantity could be traded at the prevailing international terms of trade and one in which all trade stops. Like most other studies on the topic we treat the subjective probability of trade disruption as an exogenous variable. It seems, however, very well possible to treat the subjective probability as a function of the trade volume, as Bhagwati and Srinivasan (1976) do. This question is left for further research, because it would complicate the present analysis unnecessarily. ${ }^{1}$

Section 2 starts with the two-commodities case and investigates the formal properties of the model. We are especially interested in the optimality of social versus private decision making. Section 3 provides a numerical example. The final section summarizes and discusses the main findings. In the Appendix we generalize the model for an arbitrary, but finite, number of goods.

\section{THE TWO COMMODITIES CASE}

Define a strictly concave utility function $U: \mathbb{R}_{+}^{2} \rightarrow \mathbb{R}$ which possesses the usual properties; $U \in C^{2}, U_{1}>0$, and $U_{2}>0$, where subindices of functions refer to derivatives. Utility is derived from the consumption of $x$ and $y: U=U\left(C_{\mathrm{x}}, C_{\mathrm{y}}\right)$, where $C_{\mathrm{i}}$ is the consumed quantity of good $i$. Let $\phi$ be the production possibilities frontier $\phi: I \rightarrow \mathbb{R}_{+}$with $\phi \in C^{2}, \phi_{\mathrm{x}}<0$ and $\phi_{\mathrm{xx}}<0$, where $I=\left[0, x_{\mathrm{m}}\right]$ and $x_{\mathrm{m}}$ is the maximum attainable production of good $x$. In order to evaluate the expected utility of a production combination we need a function that describes the indirect utility if the free trade regime prevails and a function for the case that all trade stops.

The following setting applies to the case where the free trade regime is the actual state of the world. The usual small country assumption applies so that the international relative price $p$ of good $y$ in terms of good $x$ is exogenous and cannot be influenced $\left(p=p_{\mathrm{y}} / p_{\mathrm{x}}\right.$ ). Income $Y$ is measured in good $x$ at international prices and an indirect utility function $\vartheta(p, Y)$ is derived. $U_{1}>0$ and

1 A positive relation between trade volume and the probability of trade distuption may be deduced from the fact that the trade volume appears to be an important determinant of the success of economic sanctions in foreign policy (Van Bergeijk 1989a). Hence rational decision makers should only use sanctions against those countries with which they have substantial trade relations. 
$U_{2}>0$ imply $\vartheta_{\mathrm{Y}}>0$. The income $Y(x)$ of the production combination $(x, \phi(x))$ is by definition:

$$
Y(x) \equiv x+p \phi(x) .
$$

The 'free trade' utility function $f(x) \equiv \vartheta(p, Y(x))$ describes the indirect utility of the chosen production combination. Fig. 1 illustrates this setting graphically.

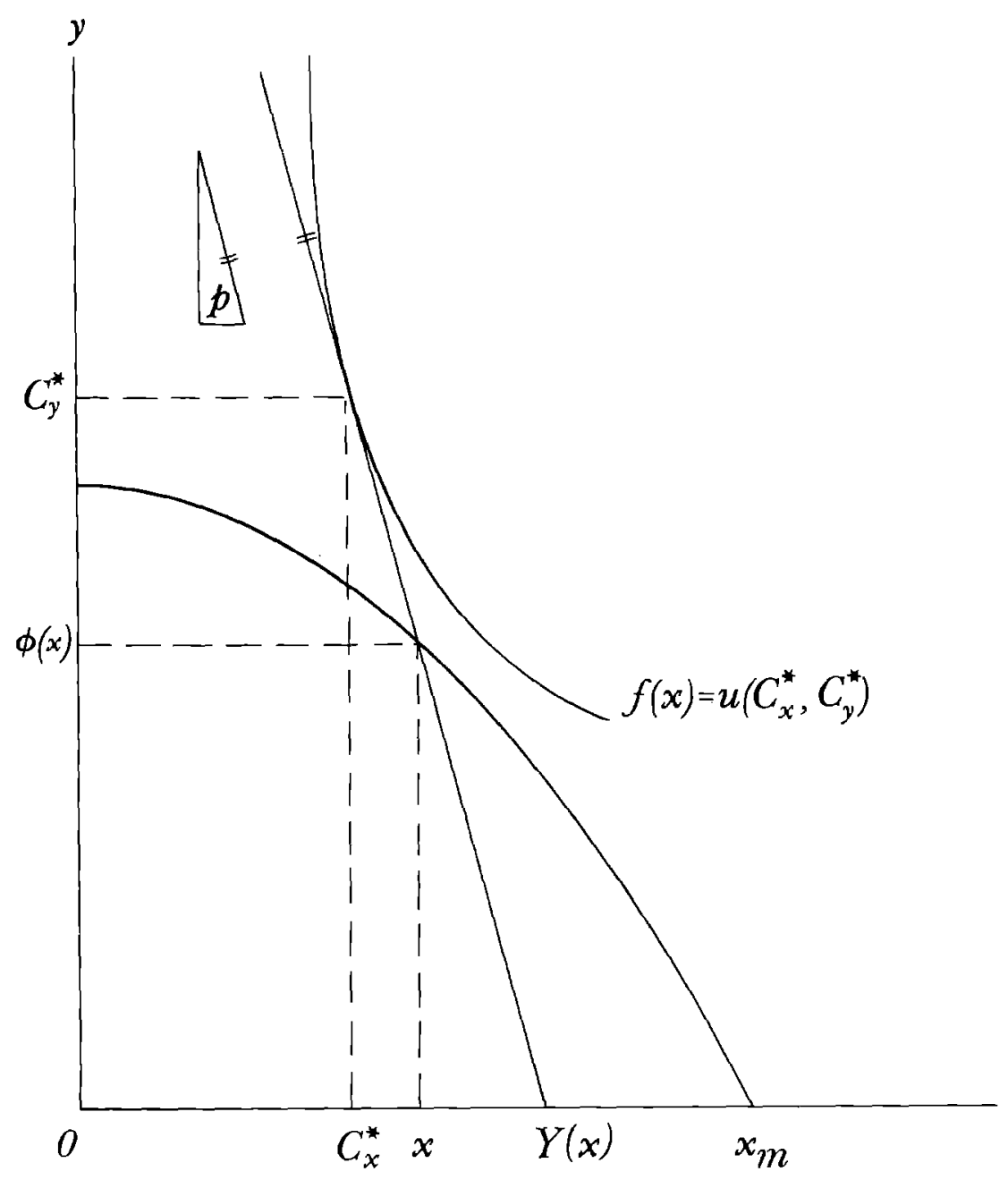

Figure 1 - Graphical representation of the introduced functions 
We adopt a two period framework and assume that producers cannot reallocate once the decision on the optimal pattern of production has been made. So the model deals essentially with a short-term horizon, since it does not allow reallocation of production factors and, in other words, assumes infinite adjustment costs.

If all trade halts and a combination $(x, \phi(x))$ is produced, the maximum attainable utility can be described by the 'non-trade' utility function, $g: I \rightarrow \mathbb{R}$, defined as $g(x) \equiv U(x, \phi(x))$. Since in the non-trade regime no foreign trade takes place, direct and indirect utility coincide. Note that a 'non-trade' production quantity only equals the traditional autarky production combination (where the indifference curve is tangent to the production possibilities curve), if individual producers and consumers, given their subjective probability that the non-trade regime will prevail, themselves decide on a production combination which does not allow for any trade. Concerning the introduced functions the following holds:

\section{Proposition 1:}

The income function and the non-trade utility function are strictly concave. $A$ sufficient condition for strict concavity of the free trade utility function is nonincreasing marginal utility of income.

\section{Proof:}

See the general case in the Appendix. Q.E.D.

Throughout the rest of the paper we will assume non-increasing marginal utility of income. ${ }^{2}$ Let $\pi$ be the subjective probability ${ }^{3}$ that the free-trade regime will be the actual state of the world once the production decision has been irrevocably made $(0 \leq \pi \leq 1)$. So the choice set may be defined as (Diagram 1):

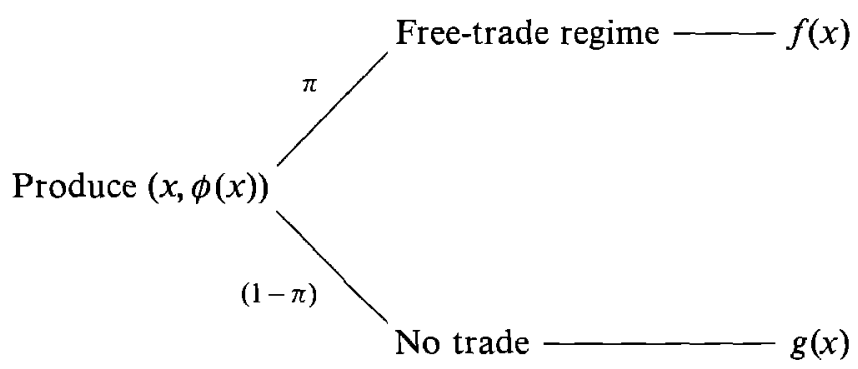

Diagram 1

2 Implying either risk-neutral or risk-averse behaviour.

3 Since probabilities will be introduced one may prefer to speak of risk rather than uncertainty (Knight [1921] 1939). Throughout this analysis, however, uncertainty is considered as a state of absent certainty. 
Assume that Von Neumann-Morgenstern (1944) expected utility is being maximized by means of collective centralized decision making, which takes the interests of both producers and consumers simultaneously into account. One may imagine a centrally planned economy or a market economy in which some sort of institution, e.g., by means of tariffs and subsidies, offers incentives to the market participants that produce the optimal production and consumption combinations. The decision problem may be formalized as follows:

\section{Optimality Problem:}

$$
\begin{array}{ll}
\max _{x} & \pi f(x)+(1-\pi) g(x) \\
\text { F.O.C. } & \pi f_{\mathrm{x}}(x)+(1-\pi) g_{\mathrm{x}}(x)=0 .
\end{array}
$$

The two-commodity case has a unique solution for the production combination $(x, y)$, the boundaries being the autarky combination and the free trade combination, as illustrated in Fig. 2. $x^{*}$ is the solution if $\pi=0$, which implies $g_{\mathrm{x}}\left(x^{*}\right)=0$, and $\tilde{x}$ is the solution if $\pi=1$, so $f_{\mathrm{x}}(\tilde{x})=0$. Assume, without loss of generality, that $0<\tilde{x}<x^{*}<x_{\mathrm{m}}$. Since $f$ and $g$ are strictly concave in $x$ it follows that

$$
x \geqq x^{*} \text { iff } g_{\mathrm{x}}(x) \lesseqgtr 0 \text { and } x \geqq \tilde{x} \text { iff } f_{\mathrm{x}}(x) \leqq 0 .
$$

More specifically, for $0<\pi<1$, we may define $x=\psi(\pi)$ as the solution to the maximization problem of equation (2) and differentiate $\psi$ with respect to $\pi$ :

$$
\psi_{\pi}=g_{\mathrm{x}} /\left\{\pi\left(\pi f_{\mathrm{xx}}+(1-\pi) g_{\mathrm{xx}}\right)\right\}<0 .
$$

So we have a strict one-to-one correspondence between on the one hand the difference between the free trade production combination and the optimal production combination and on the other hand the subjective probability $\pi$ that the free-trade regime prevails.

Will a private economy produce at the optimal point of production? This is a relevant question since producers and consumers face given prices if markets are characterized by perfect competition. Limiting cases aside, it will not. A second question pertains to the existence of a strict one-to-one relation between $\pi$ and the chosen production point.

Fig. 3 illustrates graphically the decisions facing consumers and producers. Both parties face the possibility of a non-trade and a free-trade regime. If the free-trade regime prevails, consumers maximize utility at point $A$ where the price ratio equals the international terms of trade $p$. In the non-trade regime the consumption combination $B$ results which, given the indifference curves, yields the non-trade domestic price ratio $p_{\mathrm{d}}$. Rational risk-averse expected utility maximizers prefer a price ratio between $p$ and $p_{\mathrm{d}}$, i.e. a production combination between point $C$ (where the transformation curve is tangent to the non- 


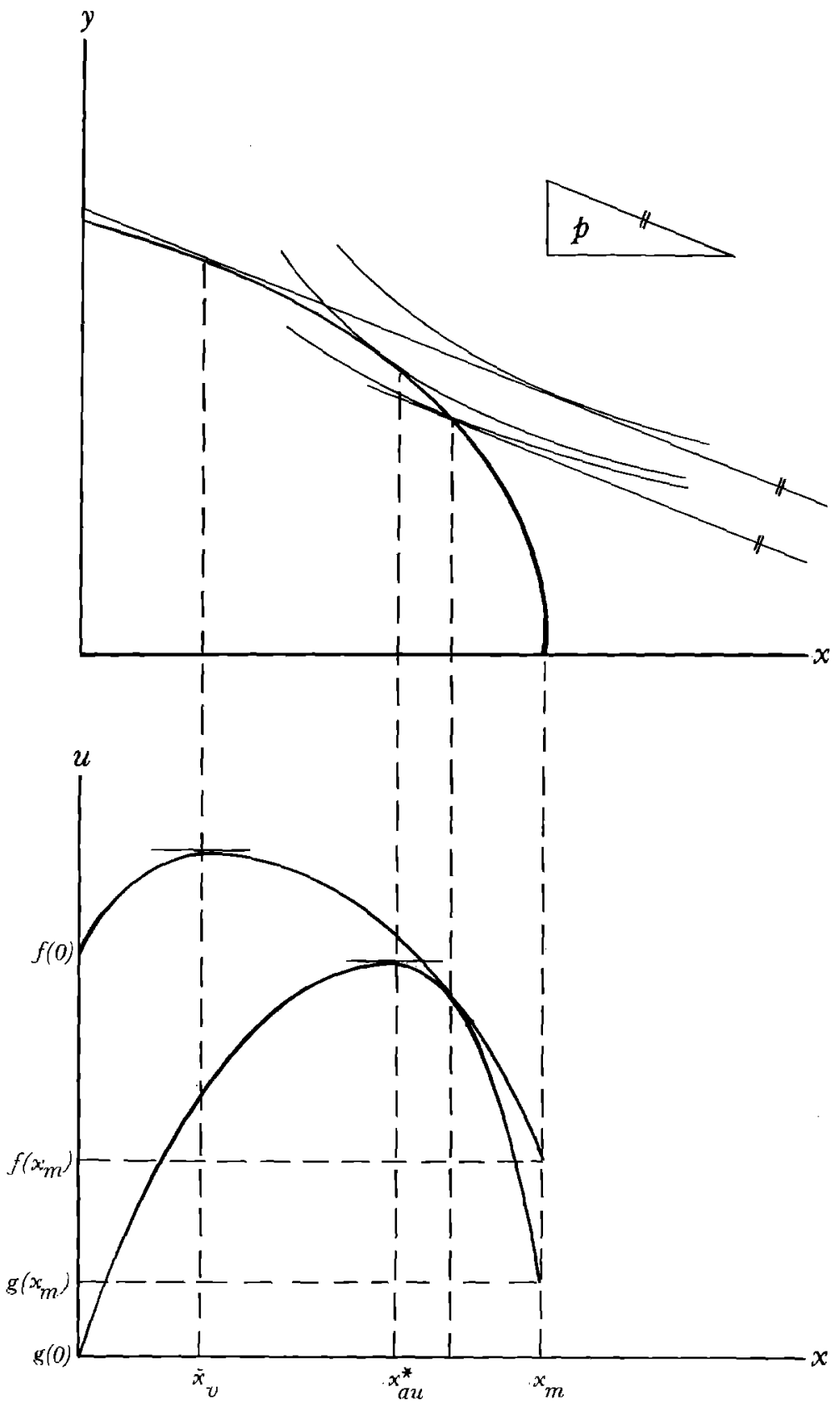

Figure 2 - The free-trade and non-trade utility-functions 


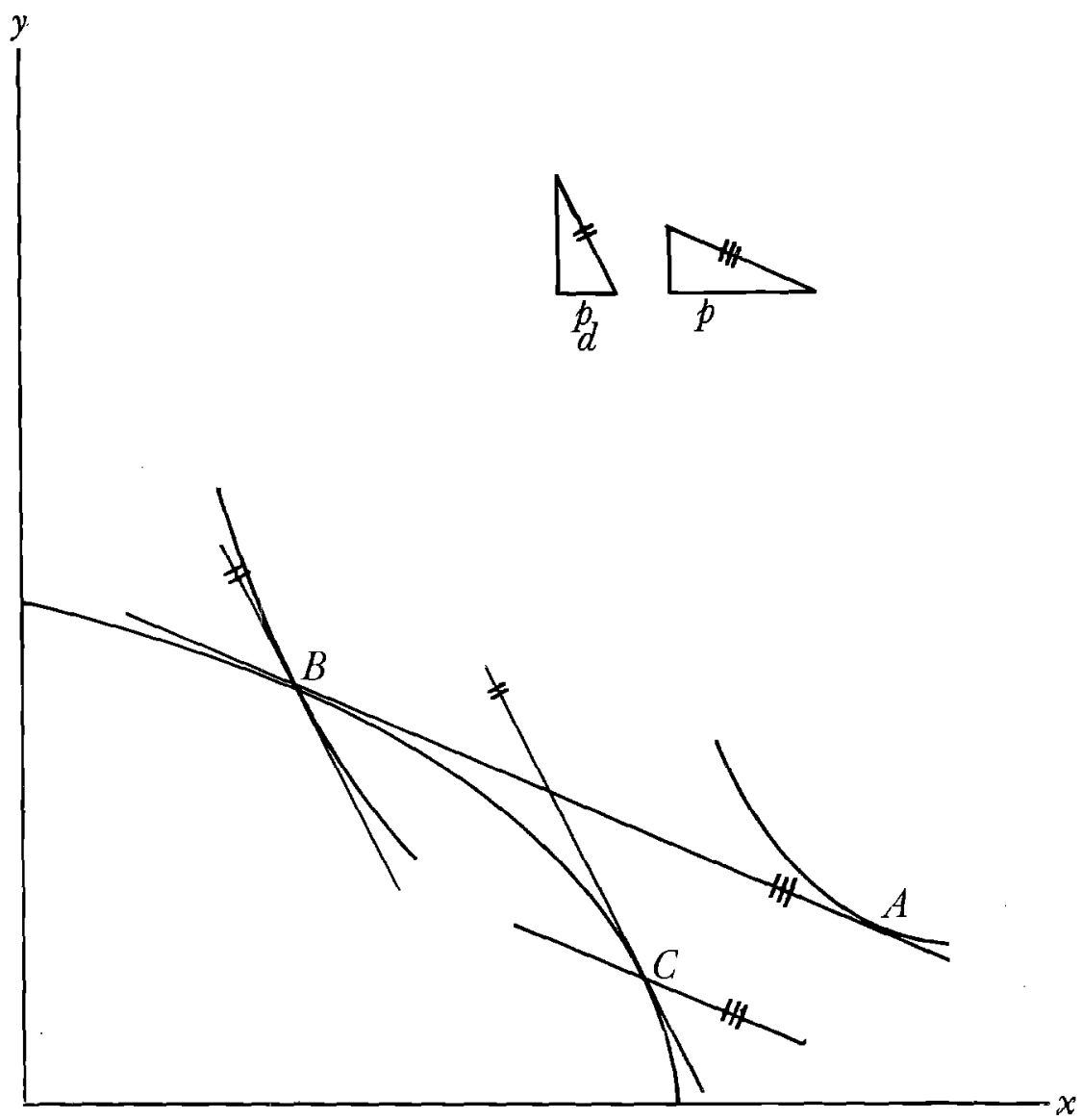

Figure 3 - Prices and quantities playing a role in consumers' and producers' decisions

trade domestic price ratio) and the free-trade production point $B$. Producers face the choice between point $C$ which would maximize their profits if the domestic non-trade price ratio equals $p_{\mathrm{d}}$ and point $B$ which maximizes their profits in the free-trade regime. Expected profit-maximizing producers will also choose a production combination between points $C$ and $B$.

We assume producers to maximize expected profits, taking prices as given. Let $p_{\mathrm{d}}$ denote domestic prices if the non-trade regime prevails. Producers solve:

Producers' Problem:

$$
\begin{array}{cl}
\max _{x} & \pi\left(x+p \phi(x)+(1-\pi)\left(x+p_{\mathrm{d}} \phi(x)\right)\right. \\
\text { F.O.C. } & {\left[\pi p+(1-\pi) p_{\mathrm{d}}\right] \phi_{\mathrm{x}}(x)+1=0 .}
\end{array}
$$


But if no trade occurs, domestic prices will have to adjust such that consumers want to consume at the point $(x, \phi(x))$, i.e. $p_{\mathrm{d}}=U_{2}(x, \phi(x)) / U_{1}(x) \equiv p_{\mathrm{d}}(x)$. The private economy equilibrium is reached when producers want to produce at the point generated by domestic prices.

Private Economy Equilibrium:

$$
\begin{aligned}
& {\left[\pi p+(1-\pi) p_{\mathrm{d}}(x)\right] \phi_{\mathrm{x}}(x)+1=0} \\
& \text { or: } \alpha(x \mid \pi)=0 .
\end{aligned}
$$

Where, obviously, $\alpha(x \mid \pi) \equiv\left[\pi p+(1-\pi) p_{\mathrm{d}}(x)\right] \phi_{\mathrm{x}}(x)+1$, which is called the private economy equilibrium function. Throughout the rest of Section 2 we will assume $p_{\mathrm{d}}$ to be a non-decreasing function of $x$. Non-negative cross marginal utility $\left(U_{12} \geq 0\right)$ is a sufficient condition. We introduce the following notation:

$\bar{x}$ - free-trade production of good $x$

$x_{\mathrm{pr}}-$ private production of $\operatorname{good} x$

$x_{0}$ - optimal production of good $x$

$x^{*}$ - autarky production of good $x$.

And we will assume, without loss of generality, that the free-trade production point produces less of good $x$ and more of good $y$ than the autarky production point, i.e. $\tilde{x}<x^{*}$ (that is, the economy has a comparative advantage in the production of $\operatorname{good} y$ ).

\section{Proposition 2:}

Both the private and the optimal point of production are in between autarky and free trade and both are unique.

\section{Proof:}

If autarky and free trade coincide, this is trivial; so assume $\tilde{x}<x^{*}$. That the optimal point of production lies in between free trade and autarky and is unique has already been shown above. As for private production, uniqueness follows easily from $\alpha_{\mathrm{x}}(x \mid \pi)<0$. Next, we need to show that the private economy equilibrium point of production is in between $\tilde{x}$ and $x^{*}$. We know, from equation (5), that $-\phi_{\mathrm{x}}\left(x^{*}\right) p_{\mathrm{d}}\left(x^{*}\right)=1=-\phi_{\mathrm{x}}(\tilde{x}) p$ and that $-\phi_{\mathrm{x}}\left(x^{*}\right)>-\phi_{\mathrm{x}}(\tilde{x})$. Therefore $p_{\mathrm{d}}\left(x^{*}\right)<p$. Take $x<\tilde{x}$, then $-\phi_{\mathrm{x}}(x)<-\phi_{\mathrm{x}}(\tilde{x})$ and $p_{\mathrm{d}}(x) \leq p_{\mathrm{d}}(\tilde{x})$. Hence:

$$
\begin{aligned}
& -\phi_{\mathrm{x}}(x)\left(\pi p+(1-\pi) p_{\mathrm{d}}(x)\right)<-\phi_{\mathrm{x}}(\tilde{x})\left(\pi p+(1-\pi) p_{\mathrm{d}}(x)\right) \\
& \quad \leq-\phi_{\mathrm{x}}(\tilde{x})\left(\pi p+(1-\pi) p_{\mathrm{d}}(\tilde{x})\right) \leq-\phi_{\mathrm{x}}(\tilde{x})\left(\pi p+(1-\pi) p_{\mathrm{d}}\left(x^{*}\right)\right) \\
& \quad<-\phi_{\mathrm{X}}(\tilde{x})(\pi p+(1-\pi) p)=1 .
\end{aligned}
$$

And $x$ cannot be a private economy equilibrium for any $\pi$. Similarly, if we take 
$x>x^{*}$, then $-\phi_{\mathrm{X}}(x)>-\phi_{\mathrm{X}}\left(x^{*}\right)$ and $p_{\mathrm{d}}(x) \geq p_{\mathrm{d}}\left(x^{*}\right)$. Hence:

$$
\begin{gathered}
-\phi_{\mathrm{x}}(x)\left(\pi p+(1-\pi) p_{\mathrm{d}}(x)\right)>-\phi_{\mathrm{K}}\left(x^{*}\right)\left(\pi p+(1-\pi) p_{\mathrm{d}}(x)\right) \\
\geq-\phi_{\mathrm{x}}\left(x^{*}\right)\left(\pi p+(1-\pi) p_{\mathrm{d}}\left(x^{*}\right)\right)=1
\end{gathered}
$$

This cannot be an equilibrium for any $\pi$ either. Q.E.D.

Note that $f_{\mathrm{x}}(x)=\vartheta_{\mathrm{Y}}(p, Y(x)) Y_{\mathrm{x}}(x)=U_{1}\left(C_{\mathrm{x}}^{*}, C_{\mathrm{y}}^{*}\right)\left(1+p \phi_{\mathrm{x}}(x)\right)$, where $\left(C_{\mathrm{x}}^{*}, C_{\mathrm{y}}^{*}\right)$ is the optimal consumption point at prices $p$ and income $Y(x)$. This is because $\vartheta_{\mathrm{Y}}$ equals the Lagrange multiplier ${ }^{4}$ which equals $U_{1}$ since $x$ serves as numéraire. Furthermore $g_{x}(x)=U_{1}(x, \phi(x))+U_{2}(x, \phi(x)) \phi_{x}(x)$. Let, for notational convenience, $U_{1}\left(U_{\mathrm{I}}^{*}\right)$ denote the marginal utility of the first consumption good evaluated at the point $(x, \phi(x))$ (respectively at $\left(C_{\mathrm{x}}^{*}, C_{\mathrm{y}}^{*}\right)$ ).

If we divide the first order condition of equation (2) by $U_{1}$ and rearrange terms, it can be written as:

$$
\begin{aligned}
& \left\{\left[\pi p+(1-\pi) p_{\mathrm{d}}(x)\right] \phi_{\mathrm{x}}(x)+1\right\}+\pi\left\{\left[\left(U_{1}^{*}-U_{1}\right) / U_{1}\right]\left(1+p \phi_{\mathrm{x}}(x)\right)\right\}=0 \\
& \text { or: } \quad \alpha(x \mid \pi)+\beta(x \mid \pi)=0 .
\end{aligned}
$$

Where $\beta(x \mid \pi) \equiv \pi\left[\left(U_{1}^{*}-U_{1}\right) / U_{1}\right]\left(1+p \phi_{x}(x)\right)$ is called the difference function as it equals the difference between the optimal and private equilibrium equation. We will assume that $U_{1}^{*}=U_{1}$ along the budget line generated by $(x, \phi(x))$ and prices $p$ if and only if the economy optimally consumes at that point. A sufficient condition is again non-negative cross marginal utility.

\section{Proposition 3:}

If trade and autarky do not coincide optimal production equals private production if and only if either autarky or free trade prevails.

\section{Proof:}

From equation (6) it follows that we need $\beta\left(x_{\mathrm{pr}} \mid \pi\right)=0$, which is the case if either $\pi=0$ (autarky) or $1+p \phi\left(x_{\mathrm{pr}}\right)=0$ (free trade). Q.E.D.

So private decision-making is inferior to collective decision-making. To be more precise:

\section{Proposition 4:}

If the probability of trade is strictly in between zero and one $(0<\pi<1)$ and free trade and autarky do not coincide the private economy will produce too much of the good in which it has a comparative advantage vis-à-vis the plan economy.

4 That is the Lagrange multiplier of the utility maximization problem, given prices $p$ and income $Y(x)$. 
Proof:

Recall $\tilde{x}<x^{*}$ (the economy has a comparative advantage in the production of good $y$ ). We want to show, with $0<\pi<1$, that the private economy produces too much of the good in which it has a comparative advantage, i.e. too much of good $y$. Therefore we need to show $\tilde{x}<x_{\mathrm{pr}}<x_{0}<x^{*}$. Since both private and optimal production are in between autarky and free trade we can restrict our attention to this region. The optimal production must satisfy equation (6): $\alpha(x \mid \pi)+\beta(x \mid \pi)=0$. We know $\alpha(x \mid \pi) \gtreqless \alpha\left(x_{\mathrm{pr}} \mid \pi\right)$ if and only if $x \leqq x_{\mathrm{pr}}$ and $\alpha\left(x_{\mathrm{pr}} \mid \pi\right)=0$. Furthermore for $x>\tilde{x}$ we have both $1+p \phi_{\mathrm{x}}(x)<0$ and $U_{1}^{*}<U_{1}$ (the economy consumes to the right of the production point with more of good $x$ and less of $\operatorname{good} y)$. Hence, with $0<\pi<1$, it follows that $\beta(x \mid \pi)$ is positive for any $x$ bigger than the free-trade production. If we now consider any production point to the left of the private production combination (but still to the right of the free-trade production combination) we have both $\alpha(x \mid \pi)>0$ and $\beta(x \mid \pi)>0$. Such a production point cannot satisfy equation (6) and therefore cannot be an optimal production point. This leads to $\tilde{x}<x_{\mathrm{pr}}<x_{0}<x^{*}$. Q.E.D.

We have established a strict one-to-one correspondence between on the one hand the probability of free trade versus trade disruption and on the other hand the extent of specialization and hence for the possibilities of international trade. The lesser extent of specialization in centrally planned economies $v i s-\grave{a}-$ vis market economies conforms to Marer's (1985, pp. 98-99) observation that

' $(\ldots)$ the consensus of experts is that the trade participation ratios of the centrally planned economies are certainly not higher and are most probably significantly lower, than those of market economies of approximately the same size and development level.'

\section{NUMERICAL EXAMPLE}

One might be tempted to argue ${ }^{5}$ that the disoptimality problem arises from the fact that producers maximize expected profits, and hence are risk-neutral, whereas consumers are risk-averse. This is not true. The most often used form of risk-neutrality is constant marginal utility of income of the indirect utility function. Even with constant marginal utility of income, however, the problem still arises, as the following simple numerical example shows. This is because the non-trade utility function's utility is not proportional to income. ${ }^{6}$ Let the

5 As was done at the Buiter Workshop Series held at the University of Groningen (May 1989).

6 The firms could, of course, be directed in the right direction by the appropriate shadow prices, see Helpman and Razin (1983). 
utility function be

$$
U\left(C_{1}, C_{2}\right)=C_{\mathrm{I}}^{1 / 2} C_{2}^{1 / 2}
$$

and the production possibilities frontier

$$
y=\phi(x)=\left(1-x^{2}\right)^{1 / 2} .
$$

Income measured in $x$ at international prices is

$$
Y(x)=x+p\left(1-x^{2}\right)^{1 / 2}
$$

Hence the 'free trade' function is

$$
f(x)=Y / 2 p^{1 / 2}=\left\{x+p\left(1-x^{2}\right)^{1 / 2}\right\} / 2 p^{1 / 2}
$$

with partial derivatives

$$
\begin{aligned}
& f_{\mathrm{x}}(x)=\left\{1-p x\left(1-x^{2}\right)^{-1 / 2}\right\}(2 p)^{-1 / 2} \gtreqless 0 \text { iff } x \leqq\left(1+p^{2}\right)^{-1 / 2} \text { and } \\
& f_{\mathrm{xx}}(x)=-\left(1-x^{2}\right)^{-3 / 2}(2 p)^{-1 / 2}<0 \text { for } 0<x<1 .
\end{aligned}
$$

The 'non-trade' function is

$$
g(x)=x^{1 / 2}\left(1-x^{2}\right)^{1 / 4}
$$

with partial derivatives

$$
\begin{aligned}
& g_{\mathrm{x}}(x)=\frac{1}{2} x^{-1 / 2}\left(1-x^{2}\right)^{-3 / 4}\left(1-2 x^{2}\right) \geqq 0 \text { iff } x \leqq\left(\frac{1}{2}\right)^{1 / 2} \text { and } \\
& g_{\mathrm{xx}}(x)=-\frac{1}{4} x^{-3 / 2}\left(1-x^{2}\right)^{-7 / 4}\left(1-2 x^{2}+4 x^{4}\right)<0 \text { for } 0<x<1 .
\end{aligned}
$$

The private economy equilibrium is reached when:

$$
\alpha(x \mid \pi)=1-\pi p x\left(1-x^{2}\right)^{-1 / 2}-(1-\pi) x^{2} /\left(1-x^{2}\right)=0 .
$$

A graphical representation for the case $p=4$ is given in Figs. 4 and 5. Table 1 summarizes for $p=2$ and $p=4$ the outcome of the model. Note that the expected price $p^{\mathrm{e}}$ has been introduced as a new symbol in the figures.

\section{CONCLUSIONS}

A small trading economy which produces and trades two goods and faces given terms of trade in combination with an uncertain volume of trade has been studied. The Appendix generalizes the analysis for an arbitrary but finite number of goods. The results of the investigation support the conclusion by Tolley 


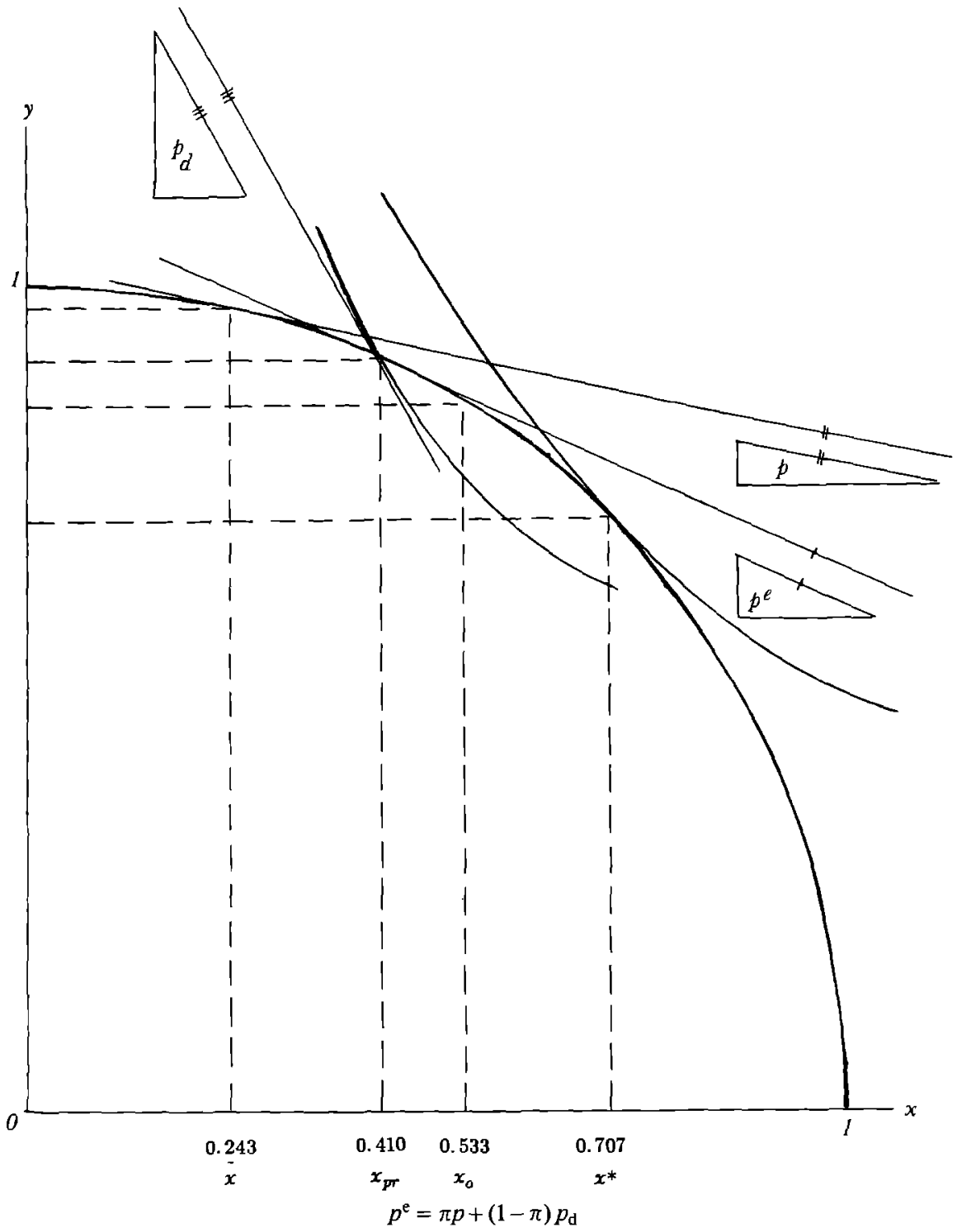

Figure 4 - Graphical representation of the numerical example

$$
\left(\pi=\frac{1}{2}, p=4 \Rightarrow p_{\mathrm{d}}=0.45\right)
$$

and Wilman (1977) that an exogenous probability of trade disruption forces public and private decision-makers to specialize to a lesser extent in accordance with their comparative advantage. There is a unique optimal point of production for each probability of trade disruption. The threat of trade disruption forces the economy away from the free-trade equilibrium towards the pure 


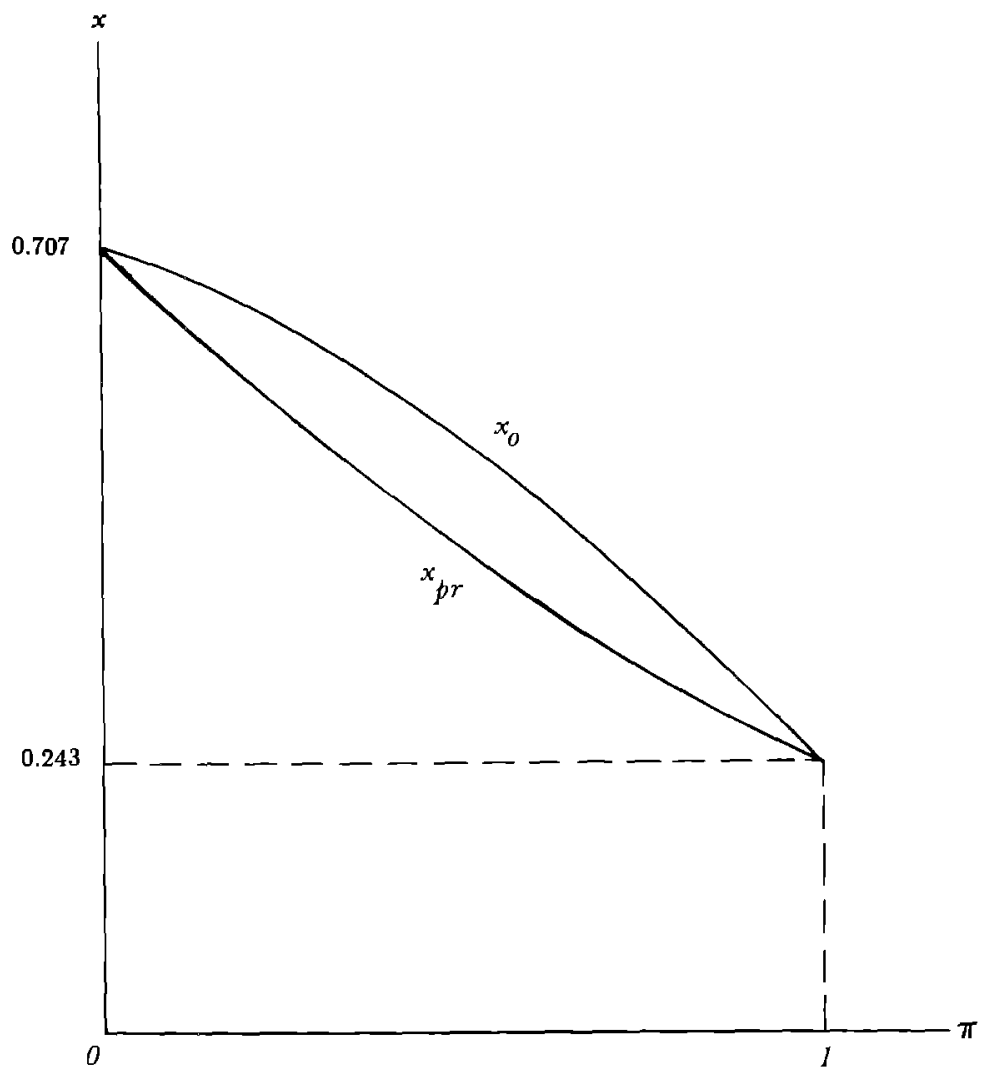

Figure 5 - Private and optimal-production of the numerical example $(p=4)$

autarkic production and consumption combinations. ${ }^{7}$ In contradistinction to Tolley and Wilman we show that the costs of trade disruptions will not be fully internalized by economic units in a general equilibrium framework.

A private competitive economy does not produce at the socially optimal production point: in the presence of uncertainty concerning the traded quantity social planning is superior to private decision making. ${ }^{8}$ We showed for the case of two goods that the private economy produces too much of the good in which it has a comparative advantage.

7 This result is important for the recent empirical literature on trade and conflict (Polachek 1980, Pollins 1988, Sayrs 1988 and Van Bergeijk 1989b), which lacks a firm theoretical foundation of the central hypothesis of a negative relation between trade and diplomatic conflict. It seems reasonable to assume that a deteriorating diplomatic climate increases the subjective probability of trade disruption. This paper links an increase in these subjective probabilities to a lower quantity of trade. 8 Even if social planning is costly there is at least in principle room for improvement, see Hurwicz (1960) and Van Marrewijk (1988). 
TABLE 1 - SIMULATION RESULTS

\begin{tabular}{|c|c|c|c|c|}
\hline \multirow[t]{2}{*}{$\pi$} & \multicolumn{2}{|c|}{$p=2$} & \multicolumn{2}{|c|}{$p=4$} \\
\hline & $x_{0}$ & $x_{\mathrm{pr}}$ & $x_{0}$ & $x_{\mathrm{pr}}$ \\
\hline 0.0 & 0.707 & 0.707 & 0.707 & 0.707 \\
\hline 0.1 & 0.694 & 0.688 & 0.679 & 0.650 \\
\hline 0.2 & 0.679 & 0.667 & 0.648 & 0.587 \\
\hline 0.3 & 0.662 & 0.644 & 0.613 & 0.523 \\
\hline 0.4 & 0.643 & 0.618 & 0.575 & 0.463 \\
\hline 0.5 & 0.622 & 0.591 & 0.533 & 0.410 \\
\hline 0.6 & 0.579 & 0.562 & 0.487 & 0.364 \\
\hline 0.7 & 0.568 & 0.533 & 0.437 & 0.326 \\
\hline 0.8 & 0.535 & 0.503 & 0.381 & 0.293 \\
\hline 0.9 & 0.495 & 0.475 & 0.318 & 0.266 \\
\hline 1.0 & 0.447 & 0.447 & 0.243 & 0.243 \\
\hline
\end{tabular}

Two general policy-relevant conclusions can be inferred from the analysis. Firstly, government intervention (e.g., by means of tariffs and/or subsidies) is desirable whenever uncertainty about the trade volume characterizes the international environment. If one opposes government intervention, a second conclusion emerges, namely that it is desirable to create clarity concerning future trade policy, i.e. by committing oneself to free trade.

\section{APPENDIX}

\section{THE GENERAL CASE}

In this Appendix we generalize the analysis to an arbitrary, but finite, number of goods. Let $\mathbf{x}$ be a vector of $n$ goods $\mathbf{x}=\left(x_{1}, \ldots, x_{\mathrm{n}}\right)^{\mathrm{T}}$ and let $y$ be the $(n+1)$-st good, which serves as numéraire. Let $\mathbf{X} \subset \mathbb{R}_{+}^{\mathrm{n}}$ be compact and convex and let $\phi: \mathbf{X} \rightarrow \mathbb{R}_{+}$be the strictly concave production possibility function, i.e. the production possibility set $\left\{(y, \mathbf{x}) \in \mathbb{R}_{+}^{\mathrm{n}+1} \mid \mathbf{x} \in \mathbf{X}\right.$ and $\left.0 \leq y \leq \phi(\mathbf{x})\right\}$ is strictly convex. Finally, let $U=(z, \mathbf{c})$ be a concave utility function with positive marginal utility, where $\mathbf{c}=\left(c_{1}, \ldots, c_{\mathbf{n}}\right)$. In the sequel $U_{\mathbf{c}}(z, \mathbf{c})$ is the vector of marginal utilities of the last $n$ goods and $U_{1}(z, \mathbf{c})$ is the first good's marginal utility. Let $\mathbf{p} \gg \mathbf{0}$ be the price vector, $\mathbf{p}=\left(p_{1}, \ldots, p_{\mathrm{n}}\right)^{\mathrm{T}}$. Define income $Y$ at international prices $\mathbf{p}$ as a function of $\mathbf{x}, Y: \mathbf{X} \rightarrow \mathbb{R}_{+}$, by $Y(\mathbf{x}) \equiv \mathbf{p}^{\mathrm{T}} \mathbf{x}+\phi(\mathbf{x})$. Let $\vartheta(\mathbf{p}, Y)$ be the indirect utility function and assume non-increasing marginal utility of income. Define the free-trade utility function, $f: \mathbf{X} \rightarrow \mathbb{R}$, by $f(\mathbf{x}) \equiv \vartheta(\mathbf{p}, Y(\mathbf{x}))$ and the non-trade utility function, $g: \mathbf{X} \rightarrow \mathbb{R}$, by $g(\mathbf{x}) \equiv U(\phi(\mathbf{x}), \mathbf{x})$.

\section{Proposition $1^{\prime}$.}

The non-trade and free-trade utility function and the income function are strictly concave. 


\section{Proof:}

Strict concavity of the income function is straightforward. Next consider the free trade utility function, $f$. Take $\mathbf{x}^{1}, \mathbf{x}^{2} \in \mathbf{X}, \mathbf{x}^{1} \neq \mathbf{x}^{2}$ and $0<\lambda<1$, then:

$$
\begin{aligned}
& f\left(\lambda \mathbf{x}^{1}+(1-\lambda) \mathbf{x}^{2}\right) \equiv \vartheta\left(\mathbf{p}, Y\left(\lambda \mathbf{x}^{1}+(1-\lambda) \mathbf{x}^{2}\right)\right) \\
& \quad>\vartheta\left(\mathbf{p}, \lambda Y\left(\mathbf{x}^{1}\right)+(1-\lambda) Y\left(\mathbf{x}^{2}\right)\right) \\
& \quad \geq \lambda \vartheta\left(\mathbf{p}, Y\left(\mathbf{x}^{1}\right)\right)+(1-\lambda) \vartheta\left(\mathbf{p}, Y\left(\mathbf{x}^{2}\right)\right) \equiv \lambda f\left(\mathbf{x}^{1}\right)+(1-\lambda) f\left(\mathbf{x}^{2}\right) .
\end{aligned}
$$

Where the first inequality uses strict concavity of the income function and positive marginal utility of income and the second inequality uses concavity of the indirect utility function with respect to income. Strict concavity of the nontrade utility function, $g$, can be shown in a similar way. Q.E.D.

Let $\pi$ be the probability that the free-trade regime will prevail once the production decision has been taken $(0 \leq \pi \leq 1)$. The optimal point of production is the solution of:

\section{Optimality Problem:}

$$
\begin{array}{ll}
\max _{\mathbf{x}} & \pi f(\mathbf{x})+(1-\pi) g(\mathbf{x}) \\
\text { F.O.C. } & \pi f_{\mathbf{x}}(\mathbf{x})+(1-\pi) g_{\mathbf{x}}(\mathbf{x})=\mathbf{0} .
\end{array}
$$

\section{Proposition 2'.}

The optimal point of production is unique and there is a one-to-one correspondence between $[0,1]$ and the set of optimal production points provided trade and autarky do not coincide.

\section{Proof:}

Uniqueness follows from strict concavity of $f$ and $g$. Let $\psi(\pi)$ be the solution function to the problem, i.e. $\psi:[0,1] \rightarrow \mathbf{X}$. Hence $\psi(0)$ is the non-trade vector of production and $\psi(1)$ is the free-trade vector of production. Let $Q$ be the solution set of $\psi$, i.e. $Q=\{\mathbf{z} \in \mathbf{X} \mid \exists \pi \in[0,1]$ such that $(\forall \mathbf{x} \in \mathbf{X}): \pi f(\mathbf{x})+(1-\pi) g(\mathbf{x}) \leq$ $\pi f(\mathbf{z})+(1-\pi) g(\mathbf{z})\}=\boldsymbol{\psi}([0,1])$. There is a strict one-to-one correspondence between $Q$ and $[0,1]$ provided free trade and autarky do not coincide. Let $\mathbf{x}^{*}$ be the non-trade equilibrium. $\mathbf{x}^{*}=\psi(0)$, and $\tilde{\mathbf{x}}$ the free-trade equilibrium, $\overline{\mathbf{x}}=$ $\boldsymbol{\psi}(1)$. Assume $\mathbf{x}^{*} \neq \tilde{\mathbf{x}}$. Let $0<\pi<1$ and assume $\mathbf{q}$ is the optimal point of production corresponding to $\pi$. The first order condition must be satisfied, i.e. $\pi f_{\mathbf{x}}(\mathbf{q})+(1-\pi) g_{\mathbf{x}}(\mathbf{q})=\mathbf{0}$. If all partial derivatives of $f$ are zero at $\mathbf{q}$, this would imply all partial derivatives of $g$ to be zero and $q$ would have to be equal to both $\mathbf{x}^{*}$ and $\tilde{\mathbf{x}}$, which are by assumption unequal. Hence at least one partial derivative of $f$ at $\mathbf{q}$ is non-zero for that derivative and we can solve uniquely for $\pi$. Q.E.D. 
Proposition $\left(2^{\prime}\right)$ says that there is a unique optimal point of production for each probability of trade and that there is a unique chance of trade corresponding to each optimal point of production.

Private enterprises maximize expected profits. Let $\mathbf{p}_{\mathrm{d}}$ be the domestic prices that prevail if no trade takes place. Producers take prices as given, so their problem becomes:

\section{Producer's Problem:}

$$
\begin{array}{ll}
\max _{\mathbf{x}} & \pi\left(\mathbf{p}^{\mathrm{T}} \mathbf{x}+\phi(\mathbf{x})\right)+(1-\pi)\left(\mathbf{p}_{\mathrm{d}}^{\mathrm{T}} \mathbf{x}+\phi(\mathbf{x})\right) \\
\text { F.O.C. } & \pi \mathbf{p}+(1-\pi) \mathbf{p}_{\mathrm{d}}+\phi_{\mathbf{x}}(\mathbf{x})=\mathbf{0} .
\end{array}
$$

But, as before, if there is no trade domestic prices will have to adjust such that consumers want to consume at the domestic point of production. Let, for notational convenience, $U_{1}$ be the marginal utility of the first (numéraire) consumption good evaluated at the point $(\phi(\mathbf{x}), \mathbf{x})$ and $U_{1}^{*}$ evaluated at the point $(z, \mathbf{c})$, where $(z, \mathbf{c})$ maximizes utility subject to prices $\mathbf{p}$ and income $Y(\mathbf{x})$. Then $\mathbf{p}_{\mathrm{d}}=\left(1 / U_{1}\right) U_{\mathbf{x}}(\phi(\mathbf{x}), \mathbf{x}) \equiv \mathbf{p}_{\mathrm{d}}(\mathbf{x})$ and private equilibrium is reached when producers want to produce at the point generated by the domestic prices, i.e.:

\section{Private Economy Equilibrium:}

$$
\begin{aligned}
& \pi \mathbf{p}+(1-\pi) \mathbf{p}_{d}(\mathbf{x})+\phi_{\mathbf{x}}(\mathbf{x})=\mathbf{0} \\
& \text { or: } \quad \alpha(\mathbf{x} \mid \pi)=\mathbf{0} .
\end{aligned}
$$

Where $\alpha(\mathbf{x} \mid \pi) \equiv \pi \mathbf{p}+(1-\pi) \mathbf{p}_{\mathrm{d}}(\mathbf{x})+\phi_{\mathbf{x}}(\mathbf{x})$ is the private economy equilibrium function. It is straightforward to check that $f_{\mathbf{x}}(\mathbf{x})=U_{1}^{*}\left(\mathbf{p}+\phi_{\mathbf{x}}(\mathbf{x})\right)$ and $g_{\mathbf{x}}(\mathbf{x})=$ $U_{1} \phi_{\mathbf{x}}(\mathbf{x})+U_{\mathbf{x}}(\phi(\mathbf{x}), \mathbf{x})$. If we fill this into equation (13), divide by $U_{1}$ and rearrange terms it can be written as:

$$
\begin{aligned}
& \left\{\pi \mathbf{p}+(1-\pi) \mathbf{p}_{\mathbf{d}}(\mathbf{x})+\phi_{\mathbf{x}}(\mathbf{x})\right\}+\pi\left[\left(U_{1}-U_{1}^{*}\right) / U_{1}\right]\left(\mathbf{p}+\phi_{\mathbf{x}}(\mathbf{x})\right)=\mathbf{0} \\
& \text { or: } \quad \alpha(\mathbf{x} \mid \pi)+\beta(\mathbf{x} \mid \pi)=\mathbf{0} .
\end{aligned}
$$

Where $\beta(\mathbf{x} \mid \pi) \equiv \pi\left[\left(U_{1}-U_{1}^{*}\right) / U_{1}\right]\left(\mathbf{p}+\phi_{\mathbf{x}}(\mathbf{x})\right)$ is the difference function.

\section{Proposition 3'.}

If trade and autarky do not coincide it is 'extremely unlikely' for optimal production to equal private production (i.e. almost only in autarky and with free trade will this be the case).

\section{Proof:}

From equation (16) we know that optimal production equals private production if and only if $\beta\left(\mathbf{x}_{\mathrm{pr}} \mid \pi\right)=\mathbf{0}$. From the definition, either $\pi=0$ (autarky) or $\mathbf{p}+\phi_{\mathbf{x}}\left(\mathbf{x}_{\mathrm{pr}}\right)=\mathbf{0}$ (free trade) will be sufficient conditions. Private and optimal 
production will also coincide if $U_{1}^{*}=U_{1}$ on the budget hyperplane generated by $\mathbf{p}$ through the point $\left(\phi\left(\mathbf{x}_{\mathrm{pr}}\right), \mathbf{x}_{\mathrm{pr}}\right)$. This is, however, the intersection of two $n$-dimensional manifolds and will generally have dimension $n-1$ and relative measure zero (that is, relative to the budget hyperplane). In this sense it is 'extremely unlikely' that $U_{1}^{*}=U_{1}$ unless we are in autarky. For the case of 2 goods $(n=1)$, as we have seen before, it will have dimension zero, and we even gave a simple sufficient condition for uniqueness. Q.E.D.

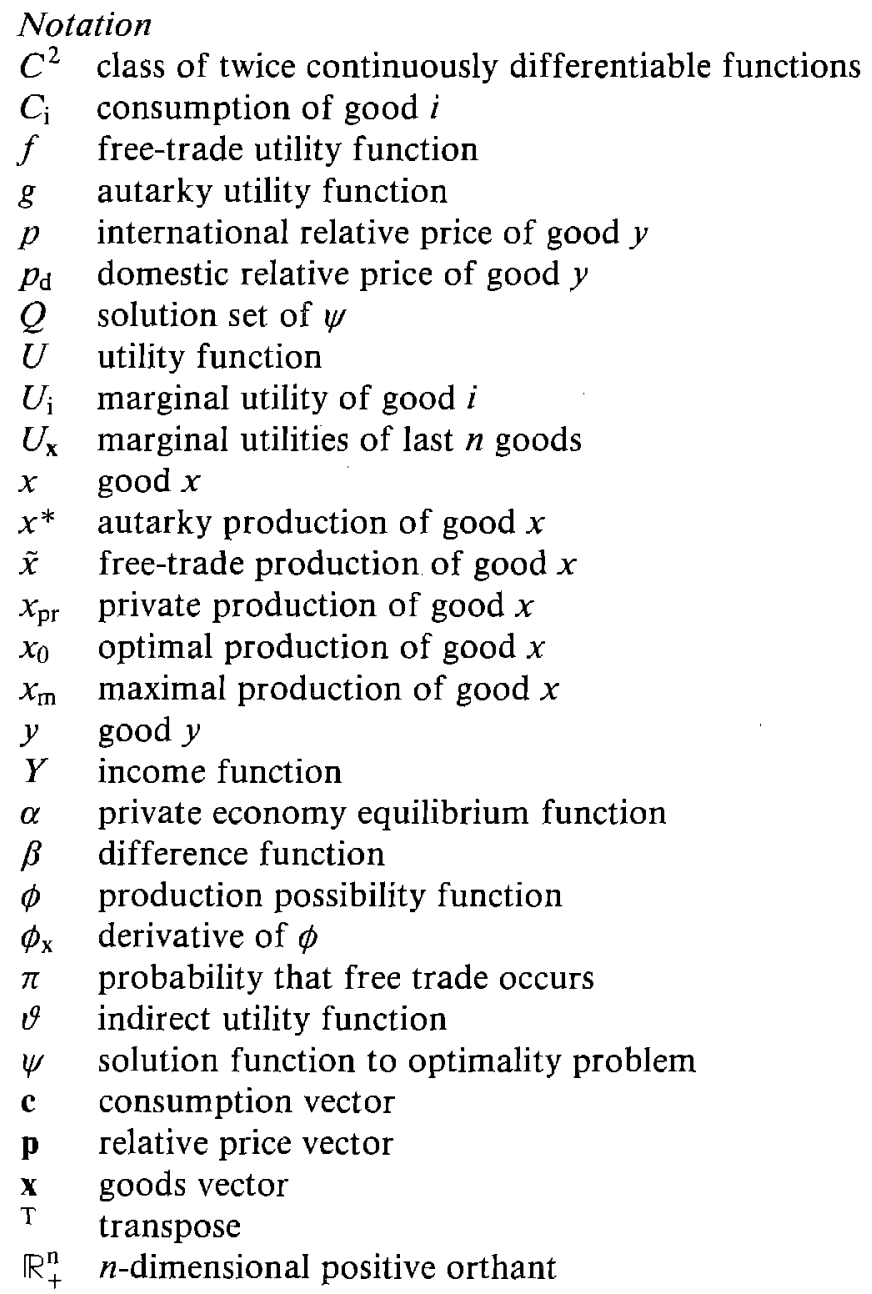




\section{REFERENCES}

Bergeijk, P.A.G. van, 'Success and Failure of Economic Sanctions,' Kyklos, XLII (1989a), pp. 385-404.

Bergeijk, P.A.G. van, 'Trade and Diplomacy. An Extension of the Gravity Analysis,' Institute of Economic Research, Research Memorandum nr. 320, University of Groningen, 1989b.

Bhagwati, J.N. and T.N. Srinivasan, 'Optimal Trade Policy and Compensation under Endogeneous Uncertainty: The Phenomenon of Market Disruption,' Journal of International Economics, VI (1976), pp. 317-336.

Helpman, E. and A. Razin, 'Increasing Returns, Monopolistic Competition, and Factor Movements,' Journal of International Economics, XIV (1983), pp. 263-276.

Hurwicz, L., 'Optimality and Informational Efficiency in Resource Allocation Process,' in: K.J. Arrow, S. Karlin and P. Suppes (eds.), Mathematical Methods in the Social Sciences, Stanford, 1960, pp. 27-36.

Knight, F.H., Risk, Uncertainty and Profit, Boston, [1921] 1939.

Marer, P., Dollar GNP's of the USSR and Eastern Europe, Baltimore, 1985.

Mayer, W., 'The National Defense Tariff Argument Reconsidered,' Journal of International Economics, VII (1977), pp. 363-377.

Marrewijk, C. van, 'Incentive Compatibility and Informational Efficiency,' Institute of Economic Research, Research Memorandum nr. 249, University of Groningen, Groningen, 1988.

Neumann, J. von and O. Morgenstern, Theory of Games and Economic Behavior, Princeton, 1944.

Polachek, S.W., 'Trade and Conflict,' Journal of Conflict Resolution, XXIV (1980), pp. 55-78.

Pollins, B., 'Does Trade Still Follow the Flag?,' Paper presented at the $3^{\text {rd }}$ World Congress of the Peace Science Society (International), Maryland, 1988.

Pomery, J., 'Uncertainty in Trade Models,' in: R.W. Jones and P.B. Kenen (eds.), Handbook of International Economics, Amsterdam, 1984, pp. 419-465.

Ruffin, R.J., 'International Trade Under Uncertainty,' Journal of International Economics, IV (1974), pp. 243-259.

Sayrs, L.W., 'New Issues in Trade and Conflict,' Occasional Papers Series, No. 79, University of Iowa, 1988.

Tolley, G.S. and J.D. Wilman, 'The Foreign Dependence Question,' Journal of Political Economy, LXXXV (1977), pp. 323-347.

\section{Summary}

\section{TRADE UNCERTAINTY AND SPECIALIZATION. SOCIAL VERSUS PRIVATE PLANNING}

A small trading economy which produces and trades an arbitrary, but finite, number of goods and faces given terms of trade in combination with an uncertain volume of trade is studied. An exogenous probability of trade disruption forces both public and private decision-makers to specialize to a lesser extent in accordance with their comparative advantage. A unique optimal point of production exists for each probability of trade disruption. A private competitive economy will not produce at this point: it produces too much of the good with a comparative advantage. 